\title{
Theorising in pragmatics: \\ Commentary on Bara's Cognitive Pragmatics: The Mental Processes of Communication \\ (MIT Press, 2010).
}

\author{
LOUISE CUMMINGS
}

In his book and article Cognitive Pragmatics, Bruno Bara presents a "unified" theoretical account of the mental processes involved in communication (Bara 2010, 2011). Through its inclusion of different strands of research, this account is broader than that advanced by any of its predecessors (e.g. Sperber and Wilson's relevance theory 1995 [1986]). In this way, the centrality of behavior games - a notion that echoes Wittgenstein's concept of a language gamebrings a much-needed social dimension to a cognitive explanation of communicative processes. The emphasis on the validation of key claims through the study of how pragmatic skills develop in children and become disrupted through disease and injury places the somewhat neglected areas of developmental pragmatics and clinical pragmatics, respectively, at the center of theoretical work in pragmatics. The use of modern brain imaging techniques (e.g., fMRI) to establish the neural correlates of communicative processes introduces the nascent discipline of neuropragmatics into pragmatic theorizing. As this list demonstrates (and it is not an exhaustive list by any means), there is plenty to engage the reader in Bara's cognitive pragmatics. The issues I want to address are the role of theorizing in pragmatics and whether a "theory" of the mental processes involved in communication is even intelligible. To this extent, while applying to Bara's proposals, my comments are also relevant to theory construction more widely in pragmatics.

It has long been recognized that the expression and recognition of intentions must be at the center of any theory that seeks to explain communication between speakers and hearers. The central role of intentions in communication can be easily demonstrated. The speaker who utters "I'm leaving early tomorrow" may be motivated to do so by a number of different communicative intentions. On one occasion, the speaker's intention in producing this utterance may simply be to inform his hearer of his travel plans. On another occasion, the speaker may produce this utterance with a view to issuing a threat to his hearer. On still other occasions, the speaker who produces this utterance may be undertaking a promise to his hearer. The identification of the particular communicative intentions that find this same utterance being used to provide 
information on some occasions, and to issue threats and make promises on other occasions, involves a set of cognitive skills in humans that is without parallel in other animal species. These skills have been variously characterized as having a theory of mind (ToM) or as engaging in mind reading. They are the focus of Bara's attempts to explain the mental processes of communication. I have argued elsewhere that although a sizeable literature now exists on ToM skills in both normally developing children and children and adults from a range of clinical populations, this literature has so far had relatively little to say about these skills in the specific context of utterance interpretation (Cummings $2009,2012 \mathrm{a}, 2013,2014)$. It is surely sensible to ask what type of ToM skills are employed by the hearer, who is trying to establish a speaker's communicative intention in producing an utterance. At least this is the type of sensible question that the pragmatist will want to ask. Indeed, it is the question to which Bara's cognitive account is chiefly directed.

Although Bara does not use the expression "theory of mind" when characterizing the mental processes involved in utterance interpretation, it is clear that it is ToM skills that he has in mind in his cognitive pragmatics. At the outset of his article, Bara (2011: 443-444) remarks:

My intention is to describe the mental states of the participants in a communicative interaction. In addition to an analytical description, I will also furnish a formal definition of the various mental states, such as belief and intention, offering a number of innovations compared to traditional treatments, thereby offering solutions to problems that have hitherto not found satisfactory explanations. The mental states introduced will then come to constitute a logical model that accounts for both the production and the comprehension of communication acts in the ongoing process of their construction. (italies added)

In his book, Bara (2010: 252) explicitly acknowledges the role of ToM skills in the comprehension of irony and deceit, two nonstandard speech acts in his account:

If a child has not mastered the theory of mind, he can in no way understand nonstandard speech acts such as irony and deceit. Indeed, this theory is crucial for the very existence of human communication, since this is an intentional activity aiming at modifying mental states in others. (italics added)

The difficulty for pragmatists who seek to explain the mental processes involved in communication is not that communicative intentions and other mental states are involved in utterance interpretation-this much is incontestable. Rather, it is that once communicative intentions and other mental states are admitted to a theory of communication, we must relinquish any prospect of giving an intelligible account of these states. It is not simply that the number of mental states involved in utterance interpretation is large (it is very large indeed), or that the content of these states reflects a broad range of interests, 
purposes and values that it would be impossible to circumscribe (an account of mental state content would be an account of life itself). It is that we cannot make sense of the type of boundary that a theory of these mental states would entail, let alone the intentions, beliefs, and knowledge that would fall within such a boundary. Different theorists have attempted to draw this boundary in different places. For the relevance theorists Sperber and Wilson, the boundary takes the form of a deductive device, which processes assumptions according to the logical entries of their constituent concepts. For Habermas, the boundary takes the form of his theory of communicative competence, a theory that was conceived in order to counter positivism's restrictive influence on the notion of rationality. It was argued in Cummings (2005a) that these communication "theories" render themselves unintelligible by an impulse to theorizing that makes it seem that we can develop a theory of communicative rationality in much the same way that we can develop theories in the physical or biological sciences (see chapters 4 and 7 in Cummings 2005a for detailed discussion). But whereas theories about physical forces or the actions of enzymes presuppose rational concepts, specifically the rational concepts that make their intelligible expression possible, the situation is quite different for a theory of communicative rationality. Such a theory cannot presuppose rational concepts when it is these concepts that are properly the focus of theorizing. Yet in the absence of these concepts, we lack the type of rational framework that is needed to make sense of and even describe the theory of communicative rationality that we take ourselves to be characterizing.

So, theorizing about the conditions and processes that make human communication possible is something quite different from theory generation in a number of other areas. The unintelligibility that attends the former type of theorizing is not an issue in the latter type of theorizing. The question now is whether Bara's attempt to produce a theory of the mental processes that are involved in communication evades the type of criticism outlined above, a criticism that has been influenced by the philosophical work of Hilary Putnam (Cummings 2005a, 2012b). According to Bara, certain speech acts are more complex than other speech acts (a fact attested to by the results of developmental and clinical studies), because they require a greater number of inferential steps on the part of the hearer in order to link them to the behavioral games of which they are moves. Inferential complexity is thus a key criterion in Bara's categorization of speech acts such as irony and deceit:

I will speak of simple irony when the interlocutor can grasp speaker meaning instantly, moving directly from the utterance to the behavior game of which the utterance may be considered a move ... I define complex irony as irony in which the interlocutor must carry out a series of inferences in order to grasp speaker meaning . . . the difficulty of an act of deception depends on the number of inferences $B$ requires to reach the hidden game, starting from A's untruthful communication act. (Bara 2011: 469-470; italies in original) 
Clearly, behavior games, "hidden" and otherwise, play a significant role in Bara's account. It is appropriate to interrogate the exact nature of that role for what insights it can bring to our current predicament. That predicament, stated briefly, is that theories of communication are unintelligible on account of their attempt to institute boundaries on the conditions and processes that make communication possible. The first thing to notice is that by casting the complexity of speech acts in terms of the number of inferences that are required to link them to a behavior game, Bara is using a social construct to ground his account of cognitive pragmatic processes (behavior games, Bara (2011: 453) remarks, are the "social framework of communication"). This shift from cognitive processes to the social domain may address a number of problems, such as the avoidance of an infinite regress in the communicative intentions that are involved in utterance interpretation. ${ }^{1}$ However, the issue that I am specifically concerned to address is whether it avoids the unintelligibility that afflicts other communication "theories," an unintelligibility that arises when we think we can theorize about the conditions (here, mental states) that make communication possible in much the same way as we can theorize about phenomena in the physical and natural world. Bara's reliance on the notion of behavior games, particularly if this notion is made to assume more than just the appearance of a Wittgensteinian concept, suggests that avoidance may be possible. To demonstrate this point, it is necessary to engage with Hilary Putnam's philosophical views and with a particular interpretation of Wittgenstein, which has had a profound influence upon them.

Putnam's philosophical ideas have assumed a position of considerable prominence in analytical philosophy over many years. His work in areas such as language, mind and science is too vast to do justice to it in this context (see Cummings 2002, 2005b) for discussion of some of Putnam's thinking in these areas). However, one argument in particular weaves its way throughout his philosophy and is relevant to our present concerns. This is Putnam's challenge to metaphysical realism. As described by Putnam (1988: 107), metaphysical realism is "a bundle of intimately associated philosophical ideas about truth." The metaphysical realist aims to explain the success of science in terms of the reference of the theories of science to subsets of the totality of all objects. The metaphysical realist's reductionism, particularly his predilection for physical description, leads him to pursue an explanation of reference in terms of a causal relation. The key feature of this relation, as characterized by the causal theorist, is that it is devoid of the very intentional notions that it may be taken to stand in explanation of. However, it is Putnam's claim that no intelligible explanation of this reference relation can proceed in the non-intentional manner typical of causal theories of reference. Prior to Putnam's Dewey Lectures, he had appeared content to express his rejection of causal theories in terms of what he believed to be their reductionist nature. With the presentation of his 
Dewey Lectures, Putnam attempted to articulate further his dissatisfaction with the metaphysical realist's position. The focus of his attention at this time shifted from the scientific reductionism, which motivates metaphysical realism, and causal theories of reference, to the question of why it seems that a reductionist approach is the only serious contender when our inquiries turn to problems in the philosophy of mind.

It is Putnam's claim that what motivates the case of reductionism is an interface conception of mind. Indeed, once one has accepted an interface conception of mind, then one must either proceed by reducing intentionality (reductionism) or explaining intentionality away (eliminativism). This interface conception of our mental functioning has been, and continues to be, enormously influential. Notwithstanding the appeal of this picture, Putnam argues, the interface conception of mind is inherently unintelligible. Its unintelligibility stems from a certain metaphysical standpoint, one that assumes that we can adopt a God's Eye point of view (to quote Putnam) from which we can compare thought and language with reality "in itself." From this standpoint, it seems that we can survey all human concepts without in turn presupposing those concepts. The difficulty with this standpoint is that it leaves us with no means of making sense of the notion of a causal relation or of a reality "in itself." For in both cases, there is no residual notion of rationality with which to understand these notions. Moreover, it is not a solution to say that we cannot compare thought and language with reality "in itself." For in employing the notion of a reality "in itself," this negative thesis falls foul of the same unintelligibility from which it is intended to be an escape. For Putnam, a way through this impasse is to be found in Wittgenstein. As James Conant remarks in the introduction to Putnam's Words and Life:

The readings of Wittgenstein's Tractatus and Philosophical Investigations that Putnam himself (now) urges are ones which take Wittgenstein to be concerned to show that the limit against which, in our philosophizing, we (imagine ourselves to) chafe is an illusory limit. On this reading of Wittgenstein ... "we cannot know the world as it is "in itself' . . not because the 'in itself' is an unreachable limit, but because the 'in itself' doesn't make sense". (Putnam 1995: xl)

Under the pressure of doing philosophy, Putnam is arguing, we proceed by examining concepts apart from their applications in the different domains of our lives. When we do eventually set about examining their applications, we can only see these concepts through a lens of metaphysically imposed standards. As James Conant has remarked, "[t]his is one way into metaphysics" (Putnam 1995: liii). Under the influence of this metaphysical impulse, we inevitably go forward by erecting standards about what must be the case in order for our thoughts to represent (refer to) reality. The typical manifestation of these standards is in the form of a philosophical theory, thus explaining 
Putnam's concern that, "what he is offering should not be taken for a philosophical theory in the traditional sense" (Putnam 1995: xi; italics in original). To overcome the domination that this metaphy sical impulse has over us and, in so doing, find a way back out of metaphysics, we must begin by looking and seeing just how concepts are applied within our various practices. This requires that we engage in a process of description, the aim of which is an accurate characterization of the consequences that a particular picture, and the concepts inherent in it, has for its user. In his Lectures and Conversations on Aesthetics, Psychology \& Religious Belief, Wittgenstein describes the considerations that are subsumed within this type of description:

"God's eye sees everything" - I want to say of this that it uses a picture.

I don't want to belittle him [the person who says it.] . .

We associate a particular use with a picture . .

What conclusions are you going to draw? ... Are eyebrows going to be talked of, in connection with the Eye of God? ...

If I say he used a picture, I don't want to say anything he himself wouldn't say. I want to say that he draws these conclusions.

Isn't it as important as anything else, what picture he does use? . . .

The whole weight may be in the picture ... When I say he's using a picture I'm merely making a grammatical remark: [What I say] can only be verified by the consequences he does or does not draw ...

All I wished to characterize was the conventions he wished to draw. If I wished to say anything more I was merely being philosophically arrogant' (1966: 71-72; italics in original).

The most outstanding feature of this descriptive process is the restrictions placed on the extent of the description. Wittgenstein doesn't want to say anything he (the user of the picture) himself wouldn't say; indeed, to say more is "being philosophically arrogant." For Putnam at least, Wittgenstein shows us the way through the unintelligibility that attends philosophical theories such as metaphysical realism. The question now is if Bara's characterization of behavior games is sufficiently Wittgensteinian in nature to allow his cognitive pragmatic theory of communication to evade a similarcharge of unintelligibility.

To recap, theories of physical and natural phenomena are distinct from theories of the communication processes that are used to describe and characterize those phenomena. The former theories presuppose rational concepts of the type that are needed to produce intelligible statements. However, the latter (communication) theories cannot presuppose these concepts when it is concepts such as meaning, reference, and sense that are the focus of theorizing. By virtue of their attempt to step outside of these concepts in the drive to present a complete analysis of them, the proponents of communication theories render 
their own statements unintelligible in nature. In this respect, a communication theory is no different from a philosophical theory like metaphysical realismboth are attempting to transcend the very concepts that confer sense on the statements contained in those theories. But in the same way that, as Putnam claims, we can talk intelligibly about mental representation and reference, even if not from a metaphysical standpoint, I believe it is also possible to talk intelligibly about the mental processes of communication. That way lies in an approach to philosophy practiced by Wittgenstein, an approach which Bara's cognitive pragmatics must now demonstrate it can replicate.

\section{Note}

1. Sperber and Wilson $(1986,1995)$ describe an "infinite regress" of communicative intentions that is involved in the interpretation of utterances. However, Bach (1999: 359) remarks that, "[a] communicative intention is ... a self-referential, or reflexive, intention. It does not involve a series of nested intentions - the speaker does not have an intention to convey something and a further intention that the first be recognized, for then this further intention would require a still further intention that it be recognized, and so on ad infinitum."

\section{References}

Bach, Kent. 1999. Grice, H. Paul. In Robert A. Wilson \& Frank Keil (eds.), The MIT encyclopedia of the cognitive sciences, 359-360. Cambridge, MA: MIT Press.

Bara, Bruno G. 2010. Cognitive pragmatics: The mental processes of communication. Cambridge, MA: MIT Press.

Bara, Bruno G. 2011. Cognitive pragmatics: The mental processes of communication. Intercultural Pragmatics 8(3). $443-485$.

Cummings, Louise. 2002. Rejecting theorising in philosophy: The urgency of Putnamian dialectic. Journal of Speculative Philosophy 16(2). 117-141.

Cummings, Louise. 2005a. Pragmatics: A multidisciplinary perspective. Edinburgh: Edinburgh University Press.

Cummings, Louise. 2005b. Interpreting Putnam's dialectical method in philosophy. Metaphilosophy 36(4). 476-489.

Cummings, Louise. 2009. Clinical pragmatics. Cambridge: Cambridge University Press.

Cummings, Louise. 2012a. Clinical pragmatics and theory of mind. In Alessandro Capone, Franco Lo Piparo, \& Marco Carapezza (eds.), Perspectives on pragmatics and philosophy. Dordrecht: Springer.

Cummings, Louise. 2012b. Theorising context: The case of clinical pragmatics. In Rita Finkbeiner, Jörg Meibauer, \& Petra Schumacher (eds.), What is a context? Theoretical and empirical approaches. Amsterdam: John Benjamins.

Cummings, Louise. 2013. Clinical pragmatics. In Yan Huang (ed.), Oxford handbook of pragmatics. Oxford: Oxford University Press.

Cummings, Louise. 2014. Pragmatic disorders and theory of mind. In Louise Cummings (ed.), Handbook of communication disorders. Cambridge: Cambridge University Press. 


\section{Louise Cummings}

Putnam, Hilary. 1988. Representation and reality. Cambridge, MA: MIT Press.

Putnam, Hilary. 1995. Words and life. Edited by James Conant. Cambridge, MA: Harvard University Press.

Sperber, Dan \& Deirdre Wilson. 1995 [1986]. Relevance: Communication and cognition. Oxford: Blackwell.

Wittgenstein, Ludwig. 1966. Lectures and conversations on aesthetics, psychology \& religious belief. Edited by Cyril Barrett. Oxford: Basil Blackwell. 